\title{
Role of FGF23 in Kidney Transplantation
}

\section{Xoana Barros and Jose-Vicente Torregrosa*}

Department of Nephrology and Renal Transplant, Hospital Clinic, Barcelona, Spain

Keywords: Fibroblast growth factor 23; Kidney transplantation; Tertiary hyperphosphatoninism; Tertiary hyperparathyroidism; Hyphophosphatemia; Calcitriol deficiency; Chronic Kidney Disease

\section{Introduction}

Mineral bone metabolism disorders in Chronic Kidney Disease (CKD) has been traditionally related to alterations in serum levels of calcium and phosphate, calcitriol deficiency and subsequent development of secondary hyperparathyroidism. Recently, a new kind of molecules, named "phosphatonines", has been described as an implicated factor, being fibroblast growth factor 23 (FGF23) the best known of them.

This bone-derived hormone regulates phosphate and calcitriol metabolism decreasing their serum levels in healthy subjects, CKD and renal transplant patients.

In this review, we summarize recent findings on FGF23 in the pathogenesis of bone-mineral disorders in CKD, emphasizing its role in kidney transplant recipients.

\section{Fibroblast Growth Factor 23}

FGF23 becomes to FGF19 subfamily, one of the 7 subfamilies of fibroblast growth factors (FGFs), formed by FGF19, FGF21 y FGF23. As a result of lower affinity for extracellular heparan sulfate, FGF23 is free to circulate as an endocrine hormone in contrast to most other FGFs that bind to matrix and thus exert their actions through paracrine and autocrine pathways exclusively $[1,2]$.

FGF23 is generated by osteocytes, and in some cases by osteoblasts, and has several effects on mineral metabolism [3].

FGF23 is a 251 glycoprotein. The N-terminal portion of the peptide binds to FGF23-R in tissues and the C-terminal portion to Klotho; thus, both the $\mathrm{N}$ and $\mathrm{C}$ terminal portions are participants in the hormone's activity [4].

The main effect of FGF23 is on phosphate metabolism.

In the kidney, 95\% of the phosphate filtered is reabsorbed by the proximal tubule cells. FGF23 inhibits renal tubular phosphate reabsorption by suppressing the expression of luminal sodiumphosphate co-transporters (NaPi) 2a and 2c [5]. Furthermore, FGF23 inhibits intestinal absorption of phosphate by suppressing the expression of co-transporter $\mathrm{NaPi} 2 \mathrm{~b}$ independently of calcitriol [6].

FGF23 also reduces levels of 1,25-dihydroxyvitamin D by inhibiting 1-hydroxylase (CYP27B1), which converts 25-hydroxivitamin D to 1,25-dihydroxyvitamin D2, and stimulating 24-hydroxylase (CYP24), which converts 1,25-dihydroxyvitamin D2 to inactive metabolites in the proximal tubule of the kidney [7].

Consistent with these findings, excessive FGF23 cause inappropriately phosphate wasting and low 1,25 (OH)2D levels, whereas depletion of FGF23 leads to hyperphosphatemia and excessive levels of calcitriol [8].

In addition, FGF23 inhibits secretion of PTH in normal physiology

Interestingly, although receptors of FGF23 are present in many tissues, only the aforementioned ones respond to the hormone, because
Klotho needs to be present in order to FGF23 exert its effect on its receptor. Klotho is a transmembrane protein which is highly expressed in the kidney and, to a lesser extent, in the PTH glands and serves as an obligate co-receptor, enabling FGF23 to interact with its receptor. Thus, Klotho is the modifier which dictates which tissues will respond to FGF23 [9].

In fact, the negative regulation of PTH seems not exert its effect in CKD animal models $[10,11]$, probably in relation to a depressed expression of Klotho and FGF23-R in hyperplasic parathyroid glands from uremic patients, which suggest a resistance to FGF23 action $[12,13]$.

\section{Regulation of FGF23}

It seems reasonable to assume that FGF23 secretion should be regulated by serum phosphate level. However, no studies have proved that serum phosphate directly regulates FGF23. Therefore, a high dietary phosphorus intake stimulates FGF23 through an unknown mechanism which does not appear to be mediated by changes in serum phosphate levels [14,15]. In fact, no changes are noted in FGF23 levels when serum phosphate is increased via IV administration [15]. On the other hand, several studies have shown a good control of FGF23 with dietary phosphorus restriction and phosphorus binders in patients with CKD [16].

1,25-dihydroxyvitamin D stimulates FGF23 secretion by a vitamin D-response elements present in the FGF23 promoter as a counterregulatory effect to increase renal phosphate clearance in the setting of enhanced gastrointestinal phosphate absorption $[17,18]$.

A clinical study also showed that administration of calcitriol to dialysis patients results in increased serum FGF23 levels [19].

\section{Determination of FGF23}

Three assays for FGF23 are available: one assay to measure C-terminal FGF23 (cFGF23) (Immunotopics, San Clemente, CA, USA); a second assay to measure intact FGF23 (iFGF23) (Kainos, Tokyo, Japan): a third assay from Immunotopics to measure iFGF23, which has shown a high inter-assay variability, so it is preferably not to use [20].

All three assays are sandwich enzyme-linked immunosorbant assays.

cFGF23 should be measured in plasma while Kainos assay recommends measuring iFGF in serum.

The antibodies in the C-terminal assay are directed against the

*Corresponding author: Jose-Vicente Torregrosa, Department of Nephrology and Renal Transplant, Hospital Clinic, Villarroel, 170, 08036 Barcelona, Spain, Tel. +34 932275444; Fax: +34 932275498; E-mail: vtorre@clinic.ub.es

Received October 15, 2011; Accepted November 19, 2011; Published November 25, 2011

Citation: Barros X, Torregrosa JV (2011) Role of FGF23 in Kidney Transplantation. J Transplant Technol Res S1:002. doi:10.4172/2161-0991.S1-002

Copyright: ( 2011 Barros X, et al. This is an open-access article distributed under the terms of the Creative Commons Attribution License, which permits unrestricted use, distribution, and reproduction in any medium, provided the original author and source are credited. 
C-terminal region of FGF23, and therefore detect both C-terminal fragments and intact FGF23. The antibodies in the intact assay are described as being directed against the C-terminal and the $\mathrm{N}$-terminal region of FGF23 and may therefore detect only iFGF23.

In vitro experiments showed that FGF-23 protein is proteolytically processed between Arg179 and Ser180, and only full-length FGF23 showed sufficient biological activity to cause hypophosphatemia [21].

Full length FGF-23 is present in the normal circulation and the reference range for healthy adults is $10-50 \mathrm{pg} / \mathrm{ml}$, as established from 104 controls [22] or $29.7+/-20 \mathrm{pg} / \mathrm{ml}$ from 118 healthy pedriatric controls [23]. The reference range of the $\mathrm{C}$-terminal assay was reported to be less than $120-150 \mathrm{RU} / \mathrm{ml}[24,25]$.

There is a good correlation between cFGF23 and iFGF23 assays $[23,25]$ except for FGF23 levels of less than $120 \mathrm{RU} / \mathrm{ml}$ by C-terminal assay [25]. The fact that the differences between two assays were found only in lower levels of FGF23 makes us think that both assays are comparable in CKD, dialysis and transplant patients when levels are above normal range.

\section{FGF23 and CKD}

An increase of FGF23 in early stages of CKD has been observed in several studies. The early increase in the production of FGF-23 and the fact that development of hyperphosphatemia does not occur until advanced stages of CKD might be explained due to resistance to phosphaturic effect of FGF-23 as the number of nephrons decreases, with the consequent increase of FGF23 with decreasing glomerular filtration rate [26,27].

The relationship between mortality and hyperphosphatemia [28] would suggest that increased FGF23 may have a beneficial effect by delaying the accumulation of phosphate in CKD. But current evidence based medicine shows FGF23 is not only a biomarker to asses phosphate load, but also a predictor of progression of CKD [29], development of refractory hyperparathyroidism [30,31] or mortality [32,33].

Several observational studies in adults suggest that increased FGF23 is independently associated with arterial stiffness, endothelial dysfunction and increased ventricular mass in elderly population, CKD and hemodialysis patients [34-38].

Recent clinical trials have shown that high FGF23 level was an independent predictor of mortality in both incident and prevalent dialysis patients independently of serum phosphate levels [32,33].

\section{Post-transplant alterations of bone mineral metabolism}

The extreme elevations of FGF23 in dialysis patients, who can manifest 100 to 1000 -fold elevations above the normal range [26], sets the stage for tertiary FGF23 excess in the event of a kidney transplant.

After transplantation, there are some mineral alterations than could be related to FGF23 effects:

- Hypophosphatemia caused by inappropriate urinary phosphate wasting affects up to $90 \%$ of patients $[39,40]$ in the early period following kidney transplantation and $6-27 \%$ of patients have persistently low serum phosphate levels for months to years [41,42]. In these patients, hypophosphatemia can contribute to complications such osteomalacia, muscle weakness and gradual bone demineralization, which in combination with steroids could predispose patients to an increased risk of fracture. Nephrocalcinosis has been proposed as a mechanism of phosphorus-associated renal toxicity [43-45], and post-transplant hypophosphatemia and hypercalcemia were associated with calcium and phosphate deposition in renal allograft [46].
Postransplant hypophosphatemia has been traditionally linked to persistence of severe secondary hyperparathyroidism from the dialysis period into post-transplant period (tertiary hyperparathyroidism) but inappropriate urinary phosphate wasting can occur despite low levels of PTH and it can persist after elevated PTH levels have normalized [47,48]. In addition, in most cases, hypophosphatemia following kidney transplantation is isolated and dissociated from concomitant hypercalcemia, which is the cardinal manifestation of hyperparathyroidism in the setting of normal renal function.

- Calcitriol deficiency persists in patients with a functioning allograft for several months following transplantation despite excessive PTH, a healthy allograft and hypophosphatemia, each of which should stimulate its production.

Currently, persistent excess of FGF-23 after transplant has been suggested as the main contributing factor to post-transplant hypophosphatemia and calcitriol deficiency despite a functioning allograft and the presence of persistent hyperparathyroidism.

\section{FGF23 and Kidney Transplant}

Data collectively suggest that although FGF23 levels decline to a range that is comparable to patients with $\mathrm{CKD}$, ongoing elevations above the normal range contribute to early post-transplant hypophosphatemia, loss of bone mineral density, survival and allograft outcome.

Hypophosphatemia: Since 2006 several groups have published observational studies about FGF23 excess and post-transplant hypophosphatemia.

The first report studied 27 patients undergoing living donor kidney transplantation with a follow-up period of 6 months. $85 \%$ of patients developed hypophosphatemia (serum phosphate $<2.6 \mathrm{mg} / \mathrm{dL}$ ) and $37 \%$ severe hypophosphatemia (serum phosphate $<1.5 \mathrm{mg} / \mathrm{dL}$ ), without episodes of hypercalcemia in any recipient. cFGF23 (Immunotopics, San Clemente, CA, USA) decreased substantially during the first week following transplantation (means: $1218+/$ - RU/mL to 557 +/- $559 \mathrm{RU} /$ $\mathrm{mL}$ ). cFGF23 was independently associated with post-transplant serum phosphate levels, urinary fractional excretion of phosphate (FEPO4), and 1,25-dihydroxyvitamin D levels (inversely). In contrast, PTH was not independently associated with any of these parameters [39].

This association between FGF23 levels at time of transplant with post-transplant phosphate levels and FEPO4 was also described in following studies [39-42,49,50].

One year later, Evenepoel et al. [40] published another single-center prospective observational study including 41 recipients of a deceased donor kidney transplant with a follow-up period of 3 months. $90 \%$ of patients developed hypophosphatemia (serum phosphate $<2.3 \mathrm{mg} /$ dL). Serum phosphate levels reached a nadir of $1.48 \pm 0.48 \mathrm{mg} / \mathrm{dL}$ at day $27+/-19$ postransplantation, being pretransplant iFGF23 the only significant predictor. Median levels of iFGF23 (Kainos, Tokyo, Japan) decreased from 1270 (498-5418) ng/L to 56 (43-89) ng/L at month three, remaining above normal range ( $>=50 \mathrm{ng} / \mathrm{L})$ in $61 \%$ of recipients.

In a subsequent longitudinal study [41], 50 renal transplant recipients (RTR) with a GFR above $30 \mathrm{ml} / \mathrm{min}$ at month 12 after transplantation were compared with GFR-matched no transplanted CKD patients. Despite tremendous decrease post-transplantation, FGF23 levels at month 3 remained significantly higher in RTR as compared with CKD patients matched for GFR. However, afterwards, FGF23 levels and urinary fractional excretion of phosphate decline to reach similar concentrations to those CKD counterparts at month 12 , 
although these remained significantly elevated compared to normal volunteers. Another study showed normal or comparable levels of FGF23 for renal function after a year [42,51].

Bone mineral density (BMD): Relation between excess of FGF23 and BMD loss was assessed in 127 incident renal transplant recipients [52]. They found a weak association between high serum FGF23 levels and low PTH levels and risk for increased BMD loss during the first post-transplant year. And these associations were independent of serum phosphate levels at month three, thus it might be that BMD changes could be independent to hypophosphatemia.

Survival and allograft loss: In a prospective cohort of 984 stable kidney transplant recipients with a median follow up of 37 months (35 to 39 months) elevated levels of C-terminal FGF23 were independently associated with increased risk of all-cause mortality and allograft loss. C-terminal FGF23 was lower than in previous reports of CKD patients with comparable estimated GFR, but it could be explained because serum samples were assessed instead of plasma [53].

\section{Therapeutic alternatives}

Oral phosphate replacement and administration of calcitriol may be ineffective when hypophosphatemia is severe because these are the primary stimuli of FGF23 secretion and would be expected to raise FGF23 levels further. In addition, these therapies could theoretically contribute to nephrocalcinosis by markedly increasing phosphaturia [55].

A recent report suggested that cinacalcet, a calcimimmetic that decreases serum PTH levels, might improve the metabolic parameters and reduce the doses of phosphate and calcitriol required to treat patients with X-linked hypophosphatemia [54]. However, additional studies are needed to determine the long-term efficacy in kidney transplant recipients.

Anti-FGF23 antibodies improve hypophosphatemia and calcitriol deficiency in animal studies of Hyp mice [56,57]. FGF23 blockade should be a target of therapy in transplant recipients with hypophosphatemia or even normal serum phosphate levels if FGF23 excess is found to contribute directly to bone loss, long-term allograft dysfunction, or cardiovascular disease, as we previously hypothesized.

\section{Conclusions}

In renal transplanted patients, recent data seems to emphasize the role of FGF23 excess in the pathogenesis of early postransplant hypophosphatemia and its association with adverse clinical outcomes like loss of bone mineral density, survival and graft loss.

\section{References}

1. Yamashita T, Yoshioka M, Itoh N (2000) Identification of a novel fibroblast growth factor, FGF-23, preferentially expressed in the ventrolateral thalamic nucleus of the brain. Biochem Biophys Res Commun 277: 494-498.

2. Itoh N, Ornitz DM (2008) Functional evolutionary history of the mouse Fgf gene family. Dev Dyn 237: 18-27.

3. Quarles LD (2008) Endocrine functions of bone in mineral metabolism regulation. J Clin Invest 118:3820-3828.

4. Yamazaki Y, Tamada T, Kasai N, Urakawa I, Aono Y, et al. (2008) Anti-FGF23 neutralizing antibodies show the physiological role and structural features of FGF23. J Bone Miner Res 23:1509-1518.

5. Saito H, Kusano K, Kinosaki M, Ito H, Hirata M, et al. (2003) Human fibroblast growth factor-23 mutants suppress $\mathrm{Na}+$-dependent phosphate co-transport activity and 1alpha,25-dihydroxyvitamin D3 production. J Biol Chem 278: 2206-2211.

6. Razzaque MS (2008) Klotho and $\mathrm{Na}+, \mathrm{K}+-\mathrm{ATP} a s e$ activity: solving the calcium metabolism dilemma ?. Nephrol Dial Transplant 23: 459-461.
7. Shimada T, Hasegawa H, Yamazaki Y, Muto T, Hino R, et al. (2004) FGF-23 is a potent regulator of vitamin $\mathrm{D}$ metabolism and phosphate homeostasis. Bone Miner Res 19: 429-435

8. Ben-Dov IZ, Galitzer H, Lavi-Moshayoff V, Goetz R, Kuro-o M, et al. (2007) The parathyroid is a target organ for FGF23 in rats. J Clin Invest 117:4003-4008.

9. Urakawa I, Yamazaki Y, Shimada T, lijima K, Hasegawa H, et al. (2006) Klotho converts canonical FGF receptor into a specific receptor for FGF23. Nature 444:770-774.

10. Galitzer H, Ben-Dov IZ, Silver J, Naveh-Many T (2010) Parathyroid cell resistance to fibroblast growth factor 23 in secondary hyperparathyroidism of chronic kidney disease. Kidney Int 77:211-218.

11. Canalejo R, Canalejo A, Martinez-Moreno JM, Rodriguez-Ortiz ME, Estepa JC et al. (2010) FGF23 fails to inhibit uremic parathyroid glands. J Am Soc Nephrol 21:1125-1135.

12. Komaba H, Goto S, Fujii H, Hamada Y, Kobayashi A, et al. (2010) Depressed expression of Klotho and FGF receptor 1 in hyperplastic parathyroid glands from uremic patients. Kidney Int 77:232-238.

13. Kumata C, Mizobuchi M, Ogata H, Koiwa F, Nakazawa A, et al. (2010) Involvement of $\alpha$-klotho and fibroblast growth factor receptor in the development of secondary hyperparathyroidism. Am J Nephrol 31:230-238

14. Nishida $Y$, Taketani $Y$, Yamanaka-Okumura $H$, Imamura $F$, Taniguchi $A$, et al (2006) Acute effect of oral phosphate loading on serum fibroblast growth factor 23 levels in healthy men. Kidney Int 70: 2141-2147.

15. Ito N, Fukumoto S, Takeuchi Y, Takeda S, Suzuki H, et al. (2007) Effect of acute changes of serum phosphate on fibroblast (FGF)23 levels in humans. J Bone Miner Metab 25:419-422.

16. Fumihiko K, Kazama JJ, Tokumoto A, Onoda N, Kato, et al. (2005) Sevelame Hydrochloride and calcium bicarbonate reduce serum fibroblast growth factor 23 levels in dialysis patients. Ther Apher and Dial 9: 336-339.

17. Saito H, Maeda A, Ohtomo S, Hirata M, Kusano K, et al. (2005) Circulating FGF-23 is regulated by 1alpha,25-dihydroxyvitamin D3 and phosphorus in vivo. J Biol Chem 280: 2543-2549.

18. Liu S, Tang W, Zhou J, Stubbs JR, Luo Q, et al. (2006) Fibroblast growth factor 23 is a counter-regulatory phosphaturic hormone for vitamin D. J Am Soc Nephrol 17:1305-1315

19. Nishi H, Nii-Kono T, Nakanishi S, Yamazaki Y, Yamashita T, et al. (2005) Intravenous calcitriol therapy increases serum concentration of fibroblast growth factor 23 in dialysis patients with secondary hyperparathyroidism. Nephron Clin Pract 101:94-99.

20. Heijboer AC, Levitus M, Vervloet MG, Lips $P$, ter Wee PM, et al. (2009) Determination of fibroblast growth factor 23. Ann Clin Biochem 46: 338-340.

21. Shimada T, Muto T, Urakawa I, Yoneya T, Yamazaki Y, et al. (2002) Mutant FGF-23 responsible for autosomal-dominant hypophosphatemic rickets is resistant to proteolytic cleavage and causes hypophosphatemia in vivo. Endocrinology 143:3179-3182.

22. Yamazaki Y, Okazaki R, Shibata M, Hasegawa Y, Satoh K, et al. (2002) Increased circulatory level of biologically active full-length FGF-23 in patients with hypophosphatemic rickets/osteomalacia. J Clin Endocrinol Metab 87:4957-4960.

23. Imel EA, Peacock M, Pitukcheewanont P, Heller HJ, Leanne M, et al. (2006) Sensitivity of Fibroblast Growth Factor 23 Measurements in Tumor-Induced Osteomalacia. J Clin Endocrinol Metab 91: 2055-2061.

24. Jonsson KB, Zahradnik R, Larsson T, White KE, Sugimoto T, et al. (2003) Fibroblast growth factor-23 in oncogenic osteomalacia and X-linked hypophosphatemia. N Engl J Med 348:1656-1663.

25. Ito N, Fukumoto S, Takeuchi Y, Yasuda T, Hasegawa Y, et al. (2005) Comparison of two assays for fibroblast growth factor (FGF)-23. J Bone Miner Metab 23:435-440.

26. Larsson T, Nisbeth U, Ljunggren O, Juppner H, Jonsson KB (2003) Circulating concentration of FGF-23 increases as renal function declines in patients with chronic kidney disease, but does not change in response to variation in phosphate intake in healthy volunteers. Kidney Int 64: 2272-2279.

27. Levin A, Barkis GL, Molitch M, Smulders M, Tian J, et al. (2007) Prevalence of abnormal serum vitaminD, PTH, calcium, and phosphorus in patients with chronic kidney disease: results of the study to evaluate early kidney disease. Kidney Int 71: 31-38. 
28. Palmer SC, Hayen A, Macaskill P, Pellegrini F, Craig JC, et al. (2011) Serum levels of phosphorus, parathyroid hormone, and calcium and risks of death and cardiovascular disease in individuals with chronic kidney disease: a systematic review and meta-analysis. JAMA 305: 1119-1127.

29. Fliser D, Kollerits B, Neyer U, Ankerst DP, Lhotta K, et al. (2007) Fibroblast growth factor 23 (FGF23) predicts progression of chronic kidney disease : the mild to moderate kidney disease (MMKD) study. J Am Soc Nephrol 18: 26002608.

30. Nakanishi S, Kazama JJ, Nii-Kono T, Omori K, Yamashita T, et al. (2005) Serum fibroblast growth factor-23 levels predict the future refractory hyperparathyroidism in dialysis patients. Kidney Int 67:1171-1178

31. Kazama JJ, Sato F, Omori K, Hama H, Yamamoto S, et al. (2005) Pretreatment serum FGF- 23 levels predict the efficacy of calcitriol therapy in dialysis patients. Kidney Int 67:1120-1125.

32. Gutierrez OM, Mannstadt M, Isakova T, Rauh-Hain JA, Tamez $\mathrm{H}$, et al (2008) Fibroblast growth factor 23 and mortality among patients undergoing hemodialysis. N Engl J Med 359: 584-592.

33. Jean G, Terrat JC, Vanel T, Hurot JM, Lorriaux C, et al. (2009) High levels of serum fibroblast growth factor (FGF)-23 are associated with increased mortality in long haemodialysis patients. Nephrol Dial Transplant 24:2792-2796.

34. Mirza MA, Hansen T, Johansson L, Ahlström H, Larsson A, et al. (2009) Relationship between circulating FGF23 and total body atherosclerosis in the community. Nephrol Dial Transplant 24: 3125-3131.

35. Mirza MA, Larsson A, Melhus H, Lind L, Larsson TE (2009) Serum intact FGF23 associate with left ventricular mass, hypertrophy and geometry in an elderly population. Atherosclerosis 207 : $546-551$.

36. Hsu HJ, Wu MS (2009) Fibroblast growth factor 23: A possible cause of left ventricular hypertrophy in hemodialysis patients. Am J Med Sci 337: 116-122.

37. Gutierrez OM, Januzzi JL, Isakova T, Laliberte K, Smith K, et al. (2009) Fibroblast growth factor 23 and left ventricular hypertrophy in chronic kidney disease. Circulation 119: 2545-2552.

38. Kirkpantur A, Balci M, Gurbuz OA, Afsar B, Canbakan B, et al. (2011) Serum fibroblast growth factor-23 (FGF-23) levels are independently associated with left ventricular mass and myocardial performance index in maintenance haemodialysis patients. Nephrol Dial Transplant 26: 1346-1354.

39. Bhan I, Shah A, Holmes J, Isakova T, Gutierrez O, et al. (2006) Post-transplant hypophosphatemia: Tertiary Hyper-phosphatoninism? Kidney Int 70: 14861494.

40. Evenepoel P, Naesens M, Claes K, Kuypers D, Vanrenterghem Y (2007) Tertiary hyperphosphatoninism accentuates hypophosphatemia and suppresses calcitriol levels in renal transplant recipients. Am J Transplant 7: 1193-1200.

41. Evenepoel P, Meijers BK, De Jonge H, Naesens M, Bammens B, et al. (2008) Recovery of hyperphosphatoninism and renal phosphorus wasting one yea after successful renal transplantation. Clin J Am Soc Nephrol 3: 1829-1836.

42. Economidou D, Dovas S, Papagianni A, Pateinakis P, Memmos D (2009) FGF23 Levels before and after renal transplantation. J Transplant 2009: 379-382.

43. Schwarz A, Mengel M, Gwinner W, Radermacher J, Hiss M, et al. (2005) Risk factors for chronic allograft nephropathy after renal transplantation: A protoco biopsy study. Kidney Int 67: 341-348.

44. Pinheiro HS, Camara NO, Osaki KS, De Moura LA, Pacheco-Silva A (2005) Early presence of calcium oxalate deposition in kidney graft biopsies is associated with poor long-term graft survival. Am J Transplant 5: 323-329.

45. Habbig S, Beck BB, Feldkotter M, Körber F, Laffeber C, et al. (2009) Rena allograft calcification - prevalence and etiology in pediatric patients. Am J Nephrol 30: 194-200.

46. Evenepoel P, Lerut E, Naesens M, Bammens B, Claes K, et al. (2009) Localization, etiology and impact of calcium phosphate deposits in renal allografts. Am J Transplant 9: 2470-2478.

47. Rosenbaum RW, Hruska KA, Korkor A, Anderson C, Slatopolsky E (1981) Decreased phosphate reabsorption after renal transplantation: Evidence for mechanism independent of calcium and parathyroid hormone. Kidney Int 19: 568-578.

48. Green J, Debby H, Lederer E, Levi M, Zajicek HK, et al. (2001) Evidence for a PTH-independent humoral mechanism in post-transplant hypophosphatemia and phosphaturia. Kidney Int 60: 1182-1196.

49. Pande S, Ritter CS, Rothstein M, Wiesen K, Vassiliadis J, et al. (2006) FGF23 and sFRP-4 in Chronic Kidney Disease and Post-Renal Transplantation. Nephron Physiol 104: 23-32.

50. Trombetti A, Richert L, Hadaya K, Graf JD, Herrmann FR, et al. (2011) Early post-transplantation hypophosphatemia is associated with elevated FGF-23 levels. Eur J Endocrinol 164: 839-847.

51. Kawarazaki H, Shibagaki Y, Fukumoto S, Kido R, Nakajima I, et al. (2011) The relative role of fibroblast growth factor 23 and parathyroid hormone in predicting future hypophosphatemia and hypercalcemia after living donor kidney transplantation: a 1-year prospective observational study. Nephrol Dial Transplant 26: 2691-2695.

52. Kanaan N, Claes K, Devogelaer JP, Vanderschueren D, Depresseux G, et al (2010) Fibroblast growth factor-23 and parathyroid hormone are associated with post-transplant bone mineral density loss. Clin J Am Soc Nephrol 5: 1887 1892.

53. Wolf M, Molnar MZ, Amaral AP, Czira ME, Rudas A, et al. (2011) Elevated Fibroblast Growth Factor 23 is a Risk Factor for Kidney Transplant Loss and Mortality. J Am Soc Nephrol 22: 956-966.

54. Alon US, Levy-Olomucki R, Moore WV, Stubbs J, Liu S, et al. (2008) Calcimimetics as an adjuvant treatment for familial hypophosphatemic rickets. Clin J Am Soc Nephrol 3: 658-664

55. Caravaca F, Fernandez MA, Ruiz-Calero R, Cubero J, Aparicio A, et al. (1998) Effects of oral phosphorus supplementation on mineral metabolism of renal transplant recipients. Nephrol Dial Transplant 13: 2605-2611.

56. Yamazaki Y, Tamada T, Kasai N, Urakawa I, Aono Y, et al. (2008) Anti-FGF23 neutralizing antibodies show the physiological role and structural features of FGF23. J Bone Miner Res 23: 1509-1518.

57. Aono Y, Yamazaki Y, Yasutake J, Kawata T, Hasegawa H, et al. (2009) Therapeutic effects of anti-FGF23 antibodies in hypophosphatemic rickets/ osteomalacia. J Bone Miner Res 24: 1879-1888.
This article was originally published in a special issue, Post-Transplantation Disorders handled by Editor(s). Dr. Piergiorgio Messa, IRCCS Fondazione Ca' Granda, Italy; Dr. Cheguevara I Afaneh, Weill Cornell Medical College, USA; Dr. Shaoyan Hu, The Children's Hospital of Soochow University, China 